\title{
Analytical Approach to Predict Pre-Camber Deflection of the Pre-stressed Glulam Beams
}

\author{
Anshari, B. ${ }^{1}$
}

\begin{abstract}
A new approach to reinforce glulam timber beams using compressed wood (CW) has been developed by the Author. The compressed wood blocks are inserted into pre-cut holes on the top of glulam beams to produce pre-camber and to generate initial tensile and compressive stresses on the top and on the bottom extreme fiber of the glulam beam, respectively. A simple analytical approach has been developed to predict pre-camber deflections of the beams reinforced with three CW blocks. Assuming that moisture-dependent expansion of the CW block creates an interactive linear pressure between the glulam beam and the $\mathrm{CW}$ block, this would generate a pair of eccentric force away from the neutral axis of the beam. It is shown that the pre-camber deflection predicted at midspan of the short beams with various reinforcing arrangements give good agreement with the measured pre-camber from previous experimental results.
\end{abstract}

Keywords: Compressed wood (CW); CW reinforced glulam beam; pre-stressed; pre-camber.

\section{Introduction}

Recently, many studies on strengthening timber or glulam beam using FRP (fiber reinforced plastic) have been done, which indicated significant enhancement of bending capacity of timber or glulam beam [1-4]. Anshari et al. [5] introduced a novel way to enhance the load carrying capacity or bending capacity of glulam beam, by introducing a very small amount of compressed wood (CW) to pre-stress the beam. Compressed wood is made of a lower grade wood which is densified in radial direction under a high pressure and moderate temperature (100-180 $\left.{ }^{\circ} \mathrm{C}\right)$ condition, and becomes a wood product with high density and high strength. Figure 1 illustrates the initial thickness of softwood $\left(\mathrm{t}_{0}=50 \mathrm{~mm}\right)$ and final thickness of $\mathrm{CW}\left(\mathrm{t}_{1}=15 \mathrm{~mm}\right)$, which is produced with compression rasio (CR) of $70 \%$.

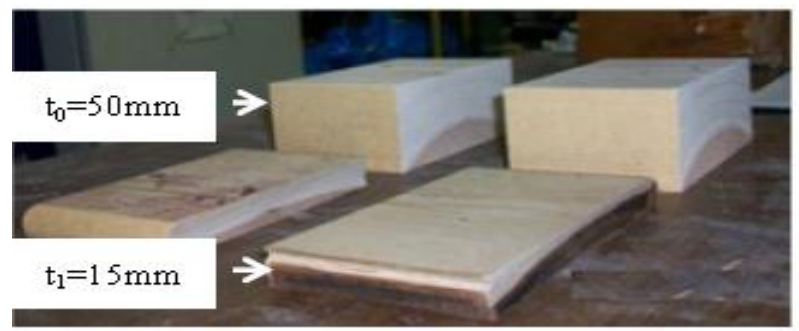

Figure 1. Typical Thickness of Softwood and Compressed Wood before and after the Compressing Process [5].

${ }^{1}$ Department of Civil Engineering, Faculty of Engineering, Mataram University, J. Majapahit No. 62, Mataram 83125, INDONESIA. E-mail: buan.anshari@unram.ac.id

Note: Discussion is expected before June, $1^{\text {st }} 2015$, and will be published in the "Civil Engineering Dimension" volume 17, number 2, September 2015.

Received 30 September 2014; revised 27 October 2014; accepted 11 March 2015.

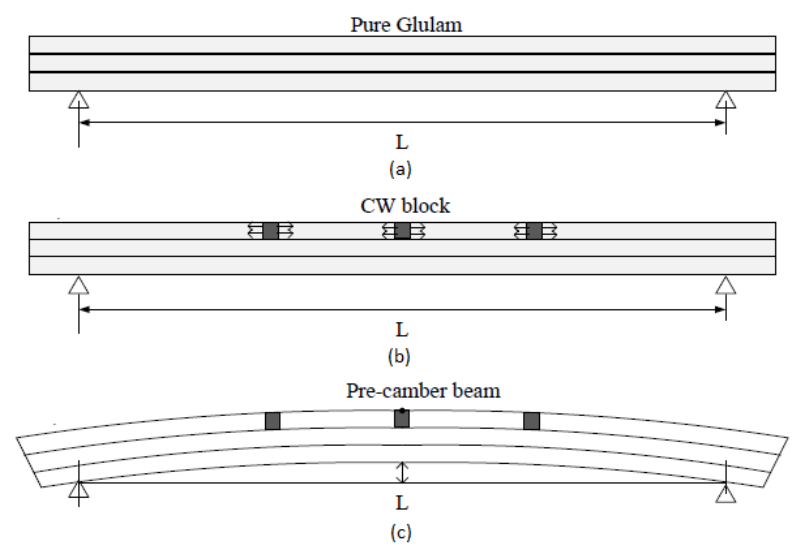

Figure 2. Mechanism of Pre-stressing Glulam Beams by using Compressed Wood Block

The technology developed is to make use of the moisture-dependent swelling nature of the compressed wood. By inserting the CW blocks on the top part of the glulam beam with the desired initial moisture content (MC) of $6 \%$, a pre-camber deflection and the related initial stresses will be building up due to the swelling. Anshari, et al. [6] developed finite element modeling of upward deflection of glulam beams reinforced by compressed wood. Anshari and Guan [7] further worked to develop FE model of initial stress and pre-camber deflection of glulam beams.

\section{Mechanism of Pre-stressing}

Figure 2 illustrates the mechanism of the prestressing process of glulam beam by using CW blocks. If the CW blocks absorb moisture from ambient it would expand in $\mathrm{R}$ direction. By expansion of the CW block, it will generate pre-camber at the mid span of the beam (see Figure 2c) and also 
generate initial compressive stress and tensile stress at the bottom and at the top extreme fibers of the beam, respectively. Once the $\mathrm{CW}$ blocks reach the equilibrium moisture content with ambient, the maximum pre-camber and initial stress will be achieved.

This study aimed to develop an analytical approach to determine pre-camber deflection of pre-stressed glulam beams using $\mathrm{CW}$ blocks.

\section{Analytical Solution Procedure}

\section{Basic Assumption}

A simple analytical approach has been developed to predict pre-camber deflections of the beams reinforced with three CW blocks. The mechanisms of the pre-camber deflection generated in the pre-stressed beam are shown in Figure 3. Assuming that moisture-dependent expansion of the CW block creates an interactive linear pressure between the glulam beam and the CW block, this would generate a pair of eccentric force away from the neutral axis of the beam. As the result, a moment couple of $\mathrm{M}_{0}$ is generated, which produces a pre-camber deflection of the strengthened beam. It is assumed that the distribution of the swelling pressure is linearly increased from zero on the top of the beam to a certain pressure $p$ at the bottom of the CW block. The CW block would expand if it absorbs moisture from ambient, because CW block is preconditioned with $\mathrm{MC}$ of $6 \%$. The dimensions of the $\mathrm{CW}$ block and the location of the CW block are shown in Figure 3.
The pressure ( $p$ ) acting on the glulam beam due to expansion of a CW block may be expressed, assuming isotropic elasticity applied, as:

$p=E_{\text {glulam }} x \varepsilon_{\text {glulam }}=E_{C W} x \varepsilon_{C W}$

where $E_{\text {glulam }}$ and $E_{C W}$ are moduli of glulam and CW, and $\varepsilon_{\text {glulam }}$ and $\mathcal{E}_{\mathrm{CW}}$ are the maximum strains on glulam and CW, respectively. The resultant force generated by the above pressure therefore is;

$F=\frac{1}{2} \times e \times f \times p$

where $e$ and $f$ are depth and width of CW block, respectively, and $p$ is the maximum pressure which is mutually acting on both the $\mathrm{CW}$ block and the glulam as shown in Figure 1. Assuming the resultant force $F$ acting at a distance ' $d$ ' away from the neutral axis of the beam, subsequently a moment couple is created as follow;

$M_{0}=F \times d$

\section{Linear Distribution of Moment along the Beam Span}

Figure 4 shows sketches to represent linear moment distribution along the beam span, which are generated by expansion of one $\mathrm{CW}$ block on the mid span, $L_{1}$, and $L_{2} \mathrm{~mm}$ away from the left support, respectively. By Macaulay methods (double integration), the pre-camber deflections corresponding to the $M_{0}$ generated at various locations of the beam can be expressed in the following equations. Here, for simplification, the same moment couple $M_{0}$ is assumed to be generated, independent of the location of the CW block.
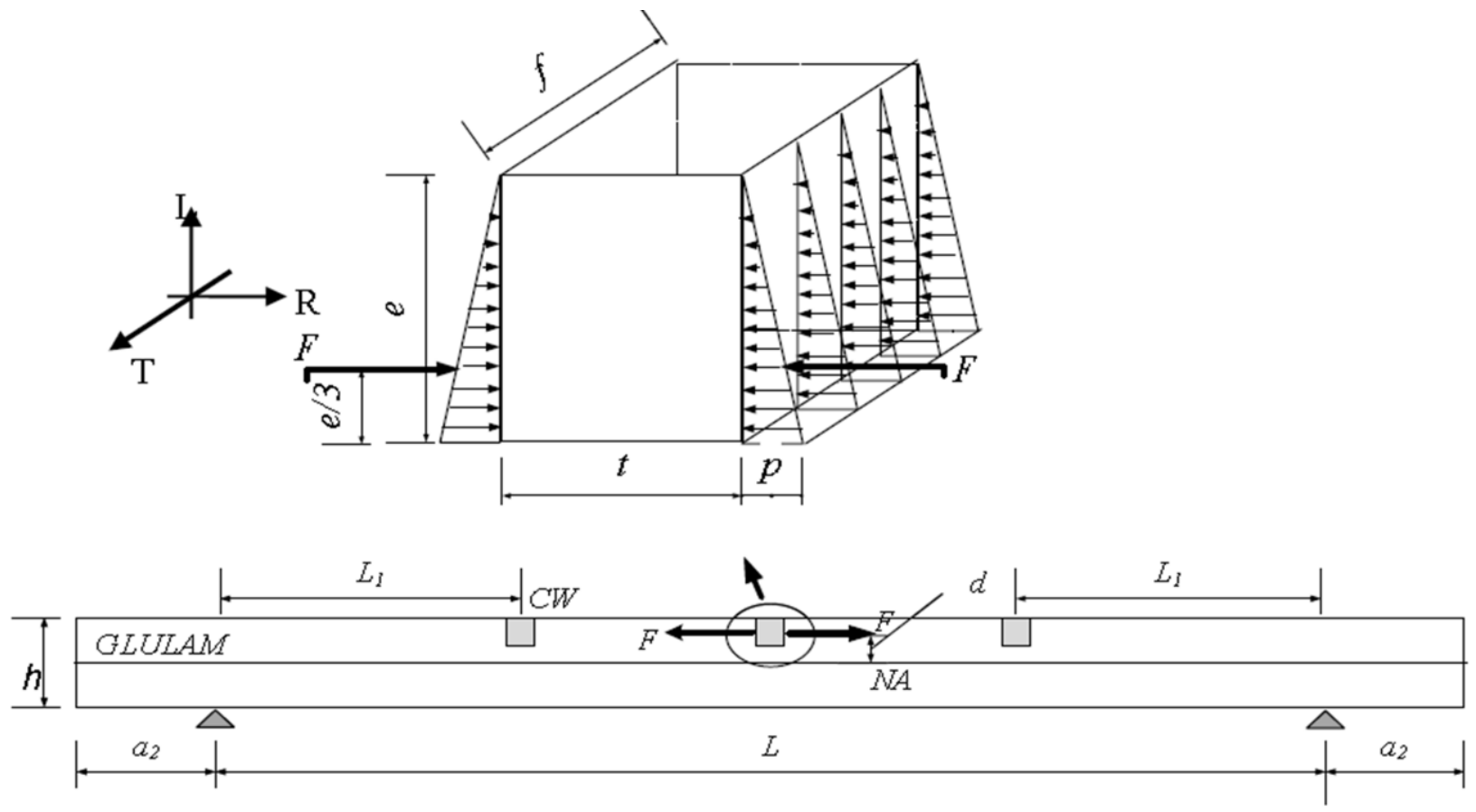

Figure 3. Beam Geometry and Detail of Distribution of Pressure along the Depth of a CW Block which is in Contact with Glulam 


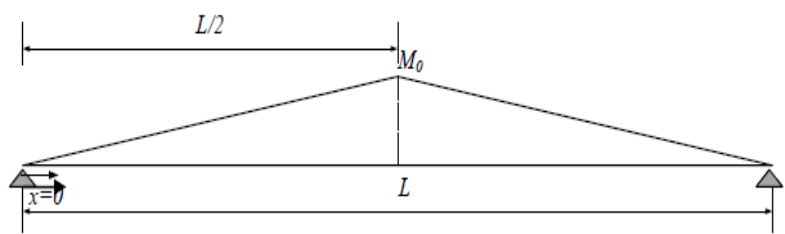

(a) Linear moment distribution due to one $\mathrm{CW}$ block at the mid span,

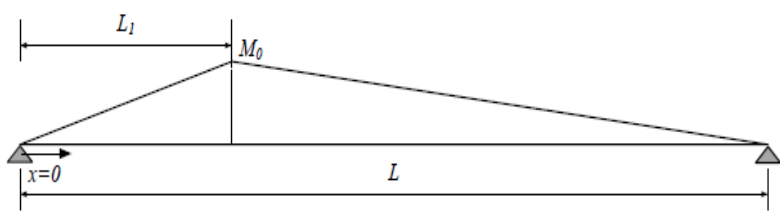

(b) Linear moment distribution due to one $\mathrm{CW}$ block at $L_{1}$ from the left support,

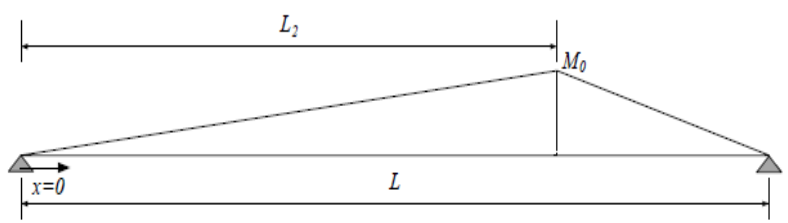

(c) Linear moment distribution due to one $\mathrm{CW}$ block at $L_{2}$ from the left support,

Figure 4. Linear Moment Distributions assumed on the Glulam Beam

Although the bending moment generated by $\mathrm{CW}$ block swelling is localized initially with building-up the pre-camber, the influence of the moment is spread to the whole beam.

Therefore, a linear distribution of the moment along the beam span is assumed, as shown in Figure 4(a). Deflection at mid span generated that was obtained can be expressed as:

$$
\begin{aligned}
& y_{1}^{L}=\frac{1}{E I} \iint M(x) d x d x \\
& \left\{\begin{array}{ll}
=\frac{1}{E I}\left(\frac{M_{0}}{3 L} x^{3}-\frac{M_{0} L}{4} x\right) & ; 0 \leq x \leq \frac{L}{2} \\
=\frac{1}{E I}\left(-\frac{M_{0}}{3 L} x^{3}+M_{0} x^{2}-\frac{3 M_{0} L}{4} x+\frac{1}{12} M_{0} L^{2}\right) & ; 0 \leq x \leq \frac{L}{2}
\end{array}\right\}
\end{aligned}
$$

where ' $E$ ' is modulus of elasticity of glulam and ' $I$ ' is second moment inertia of the beam cross-section.

Using the same procedure as those applied to one CW block at mid span, if $M_{0}$ at ' $L i$ ' away from the left support, and $\mathrm{x}$ start from left support as shown in Figure 4(b), the deflection generated can be expressed as:

$$
\begin{aligned}
& y_{2}=\frac{1}{E I} \iint M(x) d x d x=\frac{1}{E I}\left[-\frac{M_{0}}{6 L_{2}} x 3+\frac{M_{0} L}{2 L_{2}} x^{2}+\left(\frac{L_{1}^{2}}{2 L_{2}} M_{0}\right.\right. \\
& \left.\left.-\frac{L_{1}}{L_{2}} M_{0} L\right) x+-\frac{1}{3 L_{2}} M_{0} L^{3}+\frac{L_{1}}{L_{2}} M_{0} L^{2}-\frac{L_{1}^{2}}{L_{2}} M_{0} L\right]
\end{aligned}
$$

If $M_{0}$ at ' $L_{2}$ ' away from the left support, and x start from left support as shown in Figure 4(c), the deflection was obtained can be expressed as:

$$
\begin{aligned}
& y_{3}=\frac{1}{E I} \iint M(x) d x d x=\frac{1}{E I}\left[-\frac{M_{0}}{6 L_{2}} x^{3}+\frac{M_{0} L}{2 L_{2}} x^{2}+\left(\frac{L_{2}^{2}}{2 L_{1}} M_{0}\right.\right. \\
& \left.\left.-\frac{M_{0} L_{2}}{L_{1}} \mathrm{~L}\right) x+-\frac{1}{3 L_{1}} M_{0} L^{3}+\frac{L_{2}}{L_{1}} M_{0} L^{2}-\frac{L_{2}^{2}}{2 L_{1}} M_{0} L\right]
\end{aligned}
$$

Due to the symmetrical positions of the $\mathrm{CW}$ blocks at the left and the right sides, it is only necessary to determine the deflection at $L_{1} \mathrm{~mm}$ from the right support as that to the left support of the beam can be mirrored. Assuming the principle of superposition applies, the total deflection at a specific location along a pre-stressed beam with the prescribed locations of $\mathrm{CW}$ blocks may be expressed as;

$$
y_{\text {total }}^{L}=\left\{\begin{array}{c}
y_{1}^{L}, \text { one CW blok } \\
y_{1}^{L}+y_{2}^{L}+y_{3}^{L}, \text { three CW blocks }
\end{array}\right\}
$$

\section{Parabolic Distribution of Moment along the Beam Span}

Similar to the linear distribution of moment, an assumption of parabolic moment distribution can also be made. The upward deflections due to one CW block at the mid-span and one CW block at either a 1 or a from the left support can be determined based on the relationship between the pre-camber deflecttion and $M_{0}$ sketched in Figure 5. The related precambers can be calculated using Equations. 8 to 11 .

(a) for $M_{0}$ at mid span, (Figure 5)

$$
y_{1}=\frac{1}{E I} \iint M(x) d x d x=\frac{1}{E I}\left(\frac{-\mathrm{M}_{0}}{3 L^{2}} x^{4}+\frac{2}{3 L} \mathrm{M}_{0} x^{3}-\frac{1}{3} M_{0} L x\right)
$$

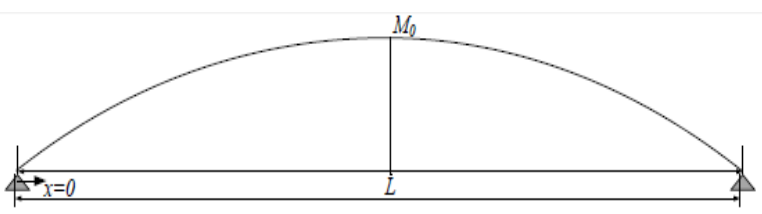

(a) Parabolic moment distribution due to one CW block at the mid span,

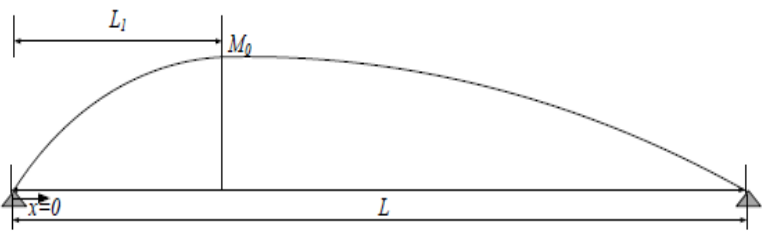

(b) Parabolic moment distribution due to one $\mathrm{CW}$ block at $L_{1}$ from the left support

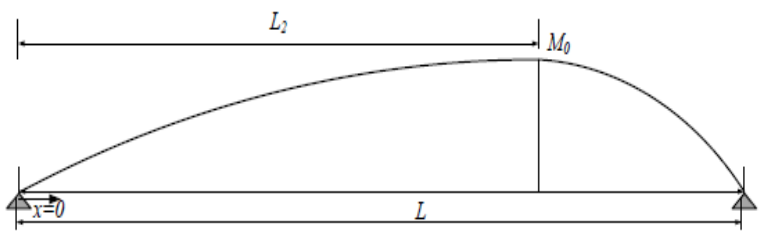

(c) Parabolic moment distribution due to one $\mathrm{CW}$ block at $L_{2}$ from the left support

Figure 5. Parabolic Moment Distributions assumed on the Glulam Beam 
(b) for $M_{0}$ at ' $L_{i}$ 'away from the left support, (Figure 5b)

$$
\begin{aligned}
& y_{2}^{P}=\frac{1}{E I} \iint M(x) d x d x \\
& =\left\{\begin{array}{c}
=\frac{1}{E I}\left(\frac{-M_{0}}{12 L L_{1}{ }^{2}} x^{4}+\frac{M_{0}}{3 L_{1}} x^{3}-\frac{2 M_{0} L_{1}}{3} x \quad ; \text { for } 0 \leq x \leq L_{1}\right. \\
=\frac{1}{E I}\left\{\begin{array}{c}
\frac{-M_{0}}{12 L_{2}{ }^{2}} x^{4}+\frac{M_{0} L_{1}}{3 L_{2}{ }^{2}} x^{3}+\frac{M_{0} L\left(L_{2}-L_{1}\right)}{2 a_{2}{ }^{2}} x^{2}+\left(-\frac{2 M_{0} L_{1}{ }^{3}}{3 a_{2}{ }^{2}}-\frac{M_{0} L L_{1}\left(L_{2}-L_{1}\right)}{a_{2}{ }^{2}}\right) x \\
+\frac{-M_{0}}{12 L_{2}{ }^{2}} L^{4}+\frac{M_{0} L_{1}}{3 L_{2}{ }^{2}} L^{3}+\frac{M_{0} L\left(L_{2}-L_{1}\right)}{2 L_{2}{ }^{2}} L^{2}+\left(-\frac{2 M_{0} L_{1}{ }^{3}}{3 L_{2}{ }^{2}}-\frac{M_{0} L L_{1}\left(L_{2}-L_{1}\right)}{L_{2}{ }^{2}}\right) L \\
; \text { for } L_{1} \leq x \leq L
\end{array}\right\}
\end{array}\right.
\end{aligned}
$$

(c) for $M_{0}$ at ' $L_{2}$ ' away from the left support, (Figure 5c)

$$
\begin{aligned}
& y_{3}^{P}=\frac{1}{E I} \iint M(x) d x d x \\
& =\left\{\begin{array}{c}
=\frac{1}{E I}\left\{\frac{-M_{0}}{12 L_{2}{ }^{2}} x^{4}+\frac{M_{0}}{3 L_{2}} x^{3}-\frac{2 M_{0} L_{2}}{3} x\right\} \quad ; \quad \text { for } 0 \leq x \leq L_{2} \\
=\frac{1}{E I}\left\{\begin{array}{c}
-\frac{M_{0}}{12 L_{1}{ }^{2}} x^{4}+\frac{M_{0} L_{2}}{3 L_{1}{ }^{2}} x^{3}+\frac{M_{0} L\left(L_{1}-L_{2}\right)}{2 L_{1}{ }^{2}} x^{2}+\left(-\frac{2 M_{0} L_{2}{ }^{3}}{3 L_{1}{ }^{2}}-\frac{M_{0} L L_{2}\left(L_{1}-L_{2}\right)}{L_{1}{ }^{2}}\right) x \\
+\frac{M_{0}}{12 L_{1}{ }^{2}} L^{4}-\frac{M_{0} L_{2}}{3 L_{1}{ }^{2}} L^{3}-\frac{M_{0} L\left(L_{1}-L_{2}\right)}{2 L_{1}{ }^{2}} L^{2}-\left(-\frac{2 M_{0} L_{2}{ }^{3}}{3 L_{1}{ }^{2}}-\frac{M_{0} L L_{2}\left(L_{1}-L_{2}\right)}{L_{1}{ }^{2}}\right) L
\end{array}\right\} \\
; \text { for } L_{2} \leq x \leq L
\end{array}\right\}
\end{aligned}
$$

Assuming the superposition principle applies, the pre-camber deflection of a beam reinforced by either one or three $\mathrm{CW}$ blocks can be determined by the following equations.

$$
y_{\text {total }}^{P}=\left\{\begin{array}{c}
y_{1}^{p} \text {, one CW blok } \\
y_{1}^{p}+y_{2}^{p}+y_{3}^{p}, \text { three CW blocks }
\end{array}\right\}
$$

If a beam is pre-stressed by five or seven CW blocks, the total pre-camber deflection can also be determined following the above procedure.

\section{Validation and Discussions}

Table 1 lists parameters used to calculate the predicted pre-camber deflections in this analytical approach, which is related to the $\mathrm{CW}$ block with a thickness (t) of $45 \mathrm{~mm}$ where the size of CW blocks is $45 \mathrm{~mm}$ in thickness, $35 \mathrm{~mm}$ in depth and $65 \mathrm{~mm}$ in width and the dimension of glulam is $105 \times 105 \times 1500$ in $\mathrm{mm}$. The iterative approach starts with assuming the stress on glulam which resulted from swelled CW. This relationship between pressure on glulam and moisture dependent swelling of $\mathrm{CW}$ was used to obtain an interactive strain on the glulam in the glulam-CW interface at the bottom of the $\mathrm{CW}$ block to produce reasonable prediction of the pre-camber deflection. The strain, shown in Table 1, was then used to work out the corresponding pressure on the glulam through Equation 1, which gives a pressure of $10 \mathrm{MPa}$ for the $45 \mathrm{~mm}$ thick CW block. The interactive strains generated on the glulam corres- ponding to the thinner CW blocks were proportionnally reduced following the related measurements of the top extreme fiber strain no. 1 as shown in Figure 6 . Therefore, the pressures generated on the glulam corresponding to CW blocks of 30 and $15 \mathrm{~mm}$ thick

\begin{tabular}{|c|c|c|}
\hline Parameter & Value & Unit \\
\hline $\begin{array}{l}\text { Elastic modulus in L direction }\left(E_{L}\right) \\
\text { of glulam }\end{array}$ & 8017 & Mpa \\
\hline $\begin{array}{l}\text { Longitudinal strain on glulam } \\
\qquad\left(\varepsilon_{\text {glulam }}\right)\end{array}$ & $1.25 \times 10^{-3}$ & $\mathrm{~mm} / \mathrm{mm}$ \\
\hline Peak pressure $(p)$ & 10 & Mpa \\
\hline Second moment inertia $(I)$ & $10.13 \times 10^{6}$ & $\mathrm{~mm}^{4}$ \\
\hline Beam span $(L)$ & 1200 & $\mathrm{Mm}$ \\
\hline $\begin{array}{l}\text { Location of a CW block at the left side } \\
\left(L_{1}\right)\end{array}$ & 340 & $\mathrm{Mm}$ \\
\hline $\begin{array}{l}\text { Location of a CW block at the right } \\
\text { side }\left(L_{2}\right)\end{array}$ & 860 & $\mathrm{Mm}$ \\
\hline Depth of the CW block (L direction) (e) & 35 & $\mathrm{Mm}$ \\
\hline Width of the CW block (T direction) $(f)$ & 65 & $\mathrm{Mm}$ \\
\hline
\end{tabular}
are 9.8 and $5.2 \mathrm{MPa}$, respectively [9].

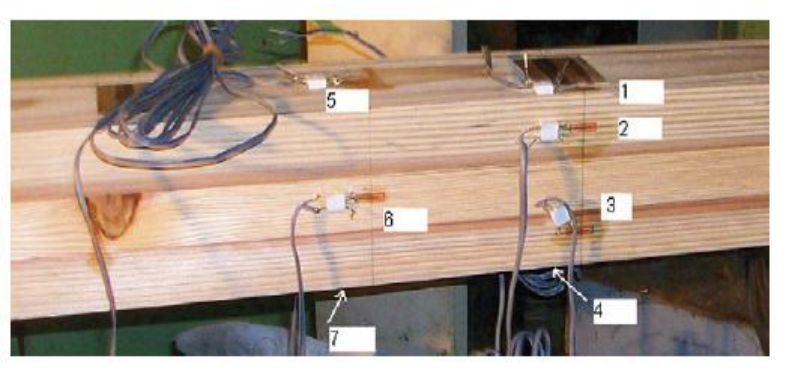

Figure 6. Location of Measured Strain [9]

Table 1. List of Parameters used in Calculations [8,9] 
Table 2. Total Deflections at Various Locations of 3CW45 with the Linear Moment Distribution assumption

\begin{tabular}{ccccc}
\hline $\begin{array}{c}\text { Location } \\
(\mathrm{mm})\end{array}$ & $\begin{array}{c}\text { Deflection } \\
(\mathrm{mm})\end{array}$ & $\begin{array}{c}\text { Total deflection } \\
(\mathrm{mm})\end{array}$ \\
\hline $\mathrm{X}$ & $y_{1}^{L}$ & $y_{2}^{L}$ & $y_{3}^{L}$ & $y_{\text {tot }}^{L}$ \\
\hline 0 & 0 & 0 & 0 & 0 \\
340 & 0.36 & 0.98 & 0.55 & 1.89 \\
600 & 0.48 & 0.86 & 0.86 & 2.20 \\
860 & 0.36 & 0.55 & 0.98 & 1.89 \\
1200 & 0 & 0 & 0 & 0 \\
\hline
\end{tabular}

Table 3. Total Deflections at Various Locations of 3CW45 with the Parabolic Moment Distribution assumption

\begin{tabular}{ccccc}
\hline $\begin{array}{c}\text { Location } \\
(\mathrm{mm})\end{array}$ & & $\begin{array}{c}\text { Deflection } \\
(\mathrm{mm})\end{array}$ & $\begin{array}{c}\text { Total deflection } \\
(\mathrm{mm})\end{array}$ \\
\hline $\mathrm{X}$ & $y_{1}^{P}$ & $y_{2}^{p}$ & $y_{3}^{P}$ & $y_{\text {tot }}^{p}$ \\
\hline 0 & 0 & 0 & 0 & 0 \\
340 & 0.46 & 1.22 & 0.72 & 2.40 \\
600 & 0.59 & 1.09 & 1.09 & 2.77 \\
860 & 0.51 & 0.72 & 1.22 & 2.40 \\
1200 & 0 & 0 & 0 & 0 \\
\hline
\end{tabular}

By substituting the parameters listed in Table 1 into all relevant Equations, the total deflections can be obtained at various locations $(0,340,600,860$ and $1200 \mathrm{~mm}$ from the left support) along the beam span. Here, the total deflection at each point was determined by superimposing the deflections from beams reinforced by CW blocks at different locations. Recapitulation of total deflection at specified location above based on the assumptions of the linear and parabolic moment distributions, respectively, are summarized in Tables 2 and 3 for 3CW45. The notation 3CW45 stands for $3 \mathrm{CW}$ blocks of $45 \mathrm{~mm}$ width.

From Table 3 with the parabolic moment distribution assumption, the total deflection of $2.77 \mathrm{~mm}$ was predicted at mid span of 3CW45, which is $20.6 \%$ higher than that of $2.20 \mathrm{~mm}$ corresponding to the linear moment distribution assumption (Table 2). This value is slightly lower than the measured precamber of $2.96 \mathrm{~mm}$ [9] for a glulam beam reinforced with three $45 \mathrm{~mm}$ thick CW blocks, 3CW45.

Figure 7 shows the comparison of the deflections from the analytical prediction and the measurement. The results indicated the analytical deflecttions related to the parabolic moment distribution correlate reasonably well to the measured ones, with less than $10 \%$ error. However, the theoretical predictions of the deflections corresponding to the linear moment distribution show relatively large discrepancies, i.e. up to $20 \%$ lower than the experimental measurement for the $45 \mathrm{~mm}$ thick $\mathrm{CW}$ reinforcement. This indicates that the linear moment distribution assumption may not be appropriate to describe the pre-stressed beams;

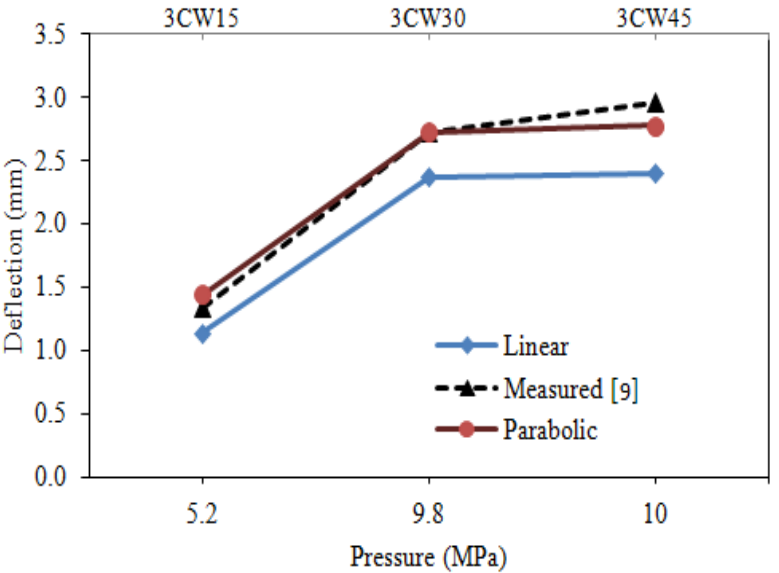

Figure 7. Comparisons of the Measured and Calculated Pre-camber Deflections at Mid-span of the Beams with Different Reinforcing Arrangements

\section{Conclusion}

Based on the simple assumptions related to the parabolic moment distribution assumption in analytical approach, the pre-camber deflection predicted at midspan of the short beams with various reinforcing arrangements give a good agreement with the measured pre-camber from experimental results. This approach is not only applicable for glulam timber but also would be suitable for solid timber.

\section{References}

1. Fiorelli, J. and Dias, A.A., Analysis of the Strength and Stiffness of Timber Beams Reinforced with Carbon Fiber and Glass Fiber, Materials Research, 6(2), 2003, pp. 193-202.

2. Fiorelli, J. and Dias, A.A., Fiberglass-reinforced Glulam Beams: Mechanical Properties and Theoretical Model, Materials Research, 9(3), 2006, pp. 263-269.

3. Johnsson, H., Blanksvärd, T., and Carolin, A., Glulam Members Strengthened by Carbon Fibre Reinforcement, Materials and Structures, 40(1), 2007, pp. 47-56.

4. Brady, J.F. and Harte, A.M., Prestressed FRP Flexural Strengthening of Softwood Glue-laminated Timber Beams, Proceeding of the $10^{\text {th }}$ World Conference on Timber Engineering (WCTE), Miyazaki, Japan, 2008

5. Anshari, B., Guan, Z.W., Kitamori, A., Jung, K. Hassel, I., and Komatsu, K., Explore Novel Ways to Strengthen Glulam Beam by Using Compressed Japanese Cedar, The Proceeding of the $11^{\text {th }}$ World Conference on Timber Engineering (WCTE), Riva del Garda, Trentino, Italy, June 20-24, 2010.

6. Anshari, B., Guan, Z.W, and Komatsu, K., Finite Element Modeling of the Pre-camber of Glulam 
Beams Reinforced by Compressed Wood, The Proceeding of the $11^{\text {th }}$ World Conference on Timber Engineering (WCTE), Riva del Garda, Trentino, Italy, June 20-24, 2010.

7. Anshari, B. and Guan, Z.W., Numerical Modelling of the Initial Stress and Upward Deflection of Glulam Beams Pre-Stressed by Compressed Wood, Applied Mechanics and Materials, 493, 2014, pp. 408-413.
8. Anshari, B., Guan, Z.W., Kitamori, A., Jung, K., Hassel, I., and Komatsu, K., Mechanical and Moisture-dependent Swelling Properties of Compressed Japanese Cedar, Construction and Building Materials, 25(4), 2011, pp. 1718-1725.

9. Anshari, B., Guan, Z.W., Kitamori, A., Jung, K., and Komatsu, K., Structural Behaviour Glued Laminated Timber Beams Pre-stressed by Compressed Wood, Construction and Building Materials, 29(4), 2012, pp. 24-32. 